\title{
Quantification of International Competitiveness of Argentine Fishing Industry
}

\author{
D’Onofrio María Victoria, González Mariela Azul, Meschino Gustavo Javier, Ballarin Virginia Laura \\ Universidad Nacional de Mar del Plata, Buenos Aires, Argentina
}

\begin{abstract}
In the 1990s, Argentine exports of fishery products increased significantly for different reasons. Competitiveness is the most important internal factor to determine a country's export performance. This factor is referenced constantly and it is considered as a necessary condition when it comes to staying in foreign markets, gaining new ones, and increasing the share of exports. This paper is a preliminary study that aims to develop a software tool which is able to characterize the competitiveness of Argentina in the international market for fishery products. We propose to use predicates generated from the knowledge of experts in the study area and evaluate them through Compensatory Fuzzy Logic. The predicates were related to obtain a value that quantifies the competitiveness of Argentina in the various markets in which it provides. The analysis of results verifies the consistency of the computer tool developed. This methodology applied to the fishing industry is an innovative approach to Argentina, not only for the sector in question but also for other industrial sectors that make up the country’s productive system.
\end{abstract}

Keywords: fishery sector, competitiveness, fuzzy logic, Compensatory Fuzzy Logic

\section{Introduction}

In Argentina during the 1990s, there were implemented measures to increase the competitiveness of productive sectors. Including trade openness, liberalization of markets and the impetus given to regional integration process aimed at enabling the easy access of domestic production in international markets. As a result of the policies implemented, the fishing industry underwent changes that directly affect the fishing pressure on marine resources. This resulted in an increase in catches to meet a growing demand for raw materials from existing industries and businesses built to export, because the higher value fish products purchased. The policy of free access to resources resulted in severe overexploitation have generated since 1998 economic impacts and social impacts, such as unemployment, have put at risk the source of livelihood of

D’Onofrio María Victoria, Master of Social Sciences, Chemical Engineer, Facultad de Ingeniería, Universidad Nacional de Mar del Plata.

González Mariela Azul, Ph.D. in Electronic Engineering and Biomedical Engineering, Facultad de Ingeniería, Universidad Nacional de Mar del Plata.

Meschino Gustavo Javier, Ph.D. in Electronic Engineering and Electronic Engineering, Facultad de Ingeniería, Universidad Nacional de Mar del Plata.

Ballarin Virginia Laura, Ph.D. in Bioengineering, Electronic Engineer, Facultad de Ingeniería, Universidad Nacional de Mar del Plata.

Correspondence concerning this article should be addressed to Facultad de Ingeniería, Universidad Nacional de Mar del Plata. Juan B. Justo 4302, Mar del Plata, Argentina. E-mail: fi.vicky@gmail.com. 
communities dependent on this activity. During the following years, measures concerning the use of fisheries resources had been taken, which led to a fall in catches, but the subsequent economic crisis in Argentina in 2001 and the consequent devaluation of the currency encouraged to keep the activity based two issues of particular relevance: exports and the harmful increase in catches of hake.

Argentina is a country which destines most of its fish production to foreign markets. This sector is considered to be one of the main sectors of the economy of Argentina, because the Argentine Sea is a source of supply for multiple marine resources. The activity focuses on a limited number of species which are sold as frozen products, with minimal processing and low value added (Zugarramurdi, Parín, Online, \& D’Onofrio, 2007). Throughout the history of the evolution of this production chain, it has not succeeded in becoming a regular and sustainable industry. Its development is subject not only to economic policies that were implemented in the country, but also to the very small role played by the Argentine government in the design of a fisheries policy that allows positive results and sustainability in the long term (D’Onofrio, 2008, 2009).

In assessing, the export performance is relevant to the concept of competitiveness and particularly important in relation to the positioning in international markets for the various productive sectors of a country. The term "competitiveness" is often used as a synonym of the concept of "comparative advantages” which, although related, are different. In the conventional theory, comparative advantage in international trade depends mainly on the relative factor endowments. International competitiveness is a concept foreign to economic theory and refers to a real situation presented by a product in an international market so distorted by market failures as the government intervention. This paper adopts the concept that identifies the competitiveness from the point of view of the results or performance of the sector in international trade, competitiveness is understood the ability of a country, an industry, a segment or an chain to gain, maintain or increase their participation in internal or external markets (IICA, 1992).

Finally, competitiveness is affected by other factors such as product quality, the degree of product differentiation, the seasonality of production and market and government policies of both the exporting country and the importing country (Contreras-Castillo, 1999). The increased competitiveness of a product in the international market is expressed in a higher export growth and increased market share.

This paper examines the export performance of the Argentine fishery products in markets that provides, during the period between 1992 and 2004. The aim is to develop a software tool which is able to characterize the competitiveness of Argentina using predicates evaluated through Compensatory Fuzzy Logic and generated from the knowledge of experts in the study area (Bonissone, 1999). The predicates were related to obtain a value that quantifies the competitiveness.

\section{Materials}

The data were obtained from the database of the United Nations Organization for Food and Agriculture (FAO-www.fao.org), and the data published by the Ministry of Agriculture, Livestock, Fisheries and Food (SAGPyA-www.sagpya.gov.ar). These databases contain tons discrimination in imports by countries in different markets and exports by destination countries Argentina, respectively. 


\section{Methods}

\section{Compensatory Fuzzy Logic}

Compensatory fuzzy logic (CFL) has proved adequate for modeling of subjective knowledge by Zadeh (1994). It presents the property that their union compensates low degrees of truth results of some fuzzy sets, with higher values of others belonging to different variables (Andrade, 2000; Meschino, 2008).

The combination in the CFL is defined using the geometric mean. The following equation shows the formal definition. Given $n$ real values $x_{i}$, the combination of determined is as follows:

$$
c\left(x_{1}, x_{2}, \ldots ., x_{n}\right)=\left(x_{1} \cdot x_{2} \ldots . x_{n}\right)^{1 / n}
$$

The disjunction is determined as 1 minus the geometric means of the denials of the truth values:

$$
d\left(x_{1}, x_{2}, \ldots, x_{n}\right)=1-\left[\left(1-x_{1}\right)\left(1-x_{2}\right) \ldots\left(1-x_{n}\right)\right]^{1 / n}
$$

The conjunction of two truth-values $x$ and $y$ is formally defined as:

$$
i(x, y)=d(n(x), c(x, y))
$$

This paper intends to evaluate predicates CFL generated from experts in the fisheries sector in Argentina and analysis of indicators of competitiveness.

First, a predicate is defined for the characterization of Argentin's competitiveness in international markets based on expert knowledge. The truth value of this predicate was determined by the CFL operators, from the truth values of simple predicates in a tree generated, which in turn are evaluated by membership functions obtained by the experts.

\section{Proposed System Predicates}

Below is the hierarchical structure of predicates proposed and evaluated, followed by their corresponding logical expressions.

$C(x, d t)=$ A country, industry or a production chain $x$ is competitive when you have the ability to win and hold, or is able to increase their participation in a given market over a period of time $d t$.

$$
C(x, d t)=G M(x, d t) \vee I N(x, d t)
$$

$G M(x, d t)=$ A country $x$ conquests and maintains a market when that market exports are equal to or greater in volume in a study period $d t$ or, if exports decrease, then increase the participation in that market.

$$
G M(x, d t)=A(x, d t) \vee[E D(x, d t) \rightarrow P A(x, d t)]
$$

$A(x, d t)=$ Exports from a country $x$ to a market are equal to or greater in volume in a study period $d t$.

$E D(x, d t)=$ Exports from a country $x$ decrease in the period $d t$.

$P A(x, d t)=$ The participation of a country $x$ in a specific market increases when the volume of exports to that market increases or if the volume exported decreases, then the total volume purchased by the market diminishes.

$$
P A(x, d t)=V A(x, d t) \vee[V D(x, d t) \rightarrow V T C(x, d t)]
$$

$V A(x, d t)=$ The export volume increases;

$V D(x, d t)=$ The export volume decreases;

$\operatorname{VTC}(x, d t)=$ The total volume purchased by the market diminishes;

$I N(x, d t)=$ A market increases when exports to that market are greater in volume over a period of study and the participation in that market increases:

$$
I N(x, d t)=E R(x, d t) \wedge A P(x, d t)
$$


$E R(x, d t)=$ Exports from one country $x$ to a market are larger in volume in a study period $d t$.

$A P(x, d t)=$ The country $x$ increases participation in that market in a study period $d t$.

The truth values of simple predicates were evaluated for three periods $(C(x)=$ The country $x$ is competitive in all periods), combining them into a single final predicate:

$$
C(x)=\underset{d t}{\wedge} C(x, d t)
$$

Because the concepts of "maintain”, “decrease”, "increase” can not be represented in the same way for large and small countries, three different models were identified, taking into account the tons exported. Thus, countries are considered large, medium or small using a membership function $\left(\mu_{P}, \mu_{M}, \mu_{G}\right)$ in each cases. For each country, they can obtain truth values that define if they are large, medium or small.

The final truth value is weighted according to the expression:

$$
\mu(c)=\frac{\mu_{P} \mu_{C P}+\mu_{M} \mu_{C P}+\mu_{G} \mu_{C P}}{\mu_{P}+\mu_{M}+\mu_{G}}
$$

Figure 1 shows the membership functions generated using the expert's knowledge.

(a)

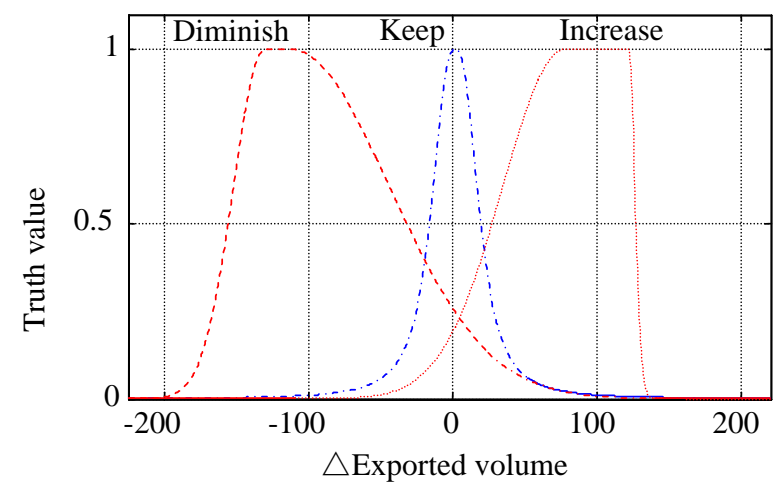

(c)

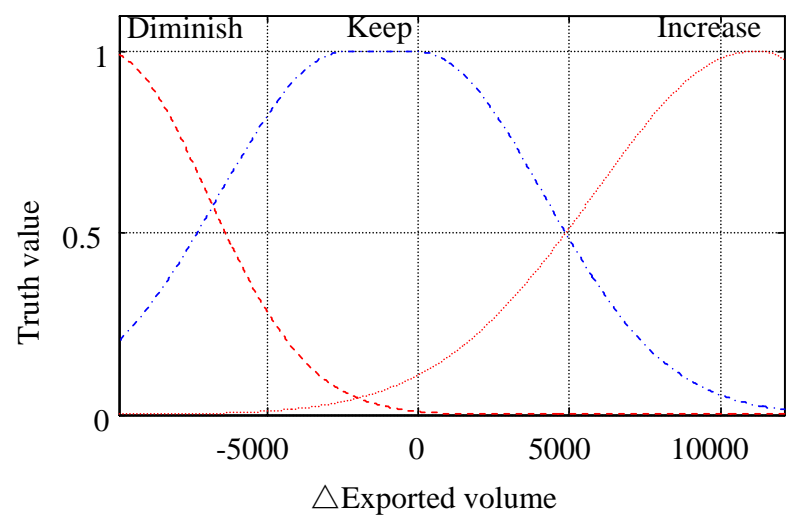

(b)

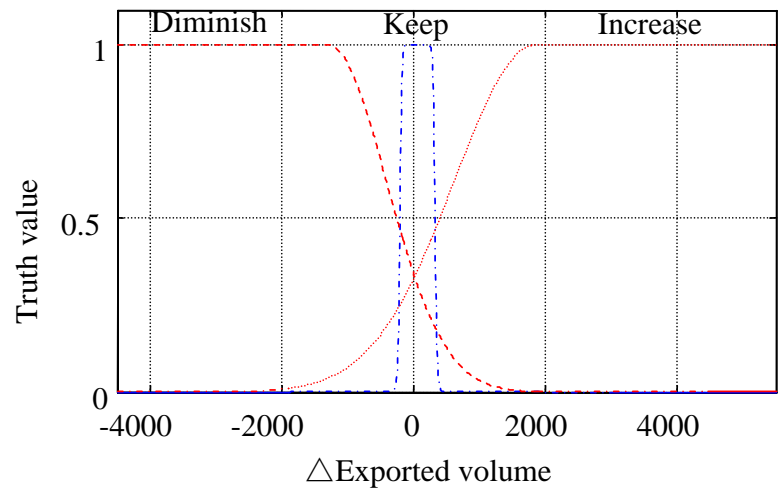

(d)

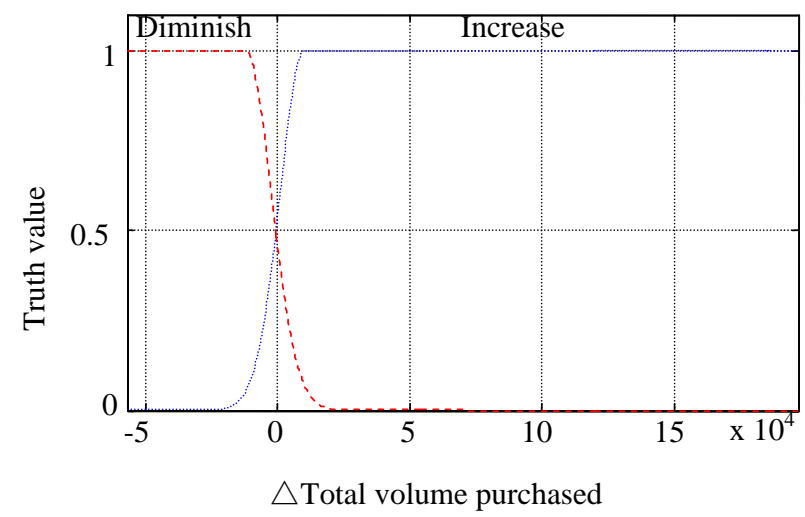

Figure 1. Membership functions: (a) tons sold by small countries Argentina buyers; (b) tons sold by Argentina to medium-sized countries buyers; (c) tons sold by Argentina to countries large buyers; (d) total tons purchased by each country in the international market. 


\section{Results}

The truth values of the final predicate are shown Table 1, they are sorted from lowest to highest (from least more competitive).

Table 1

Values Obtained for the Truth Predicate C $(x)=$ "The Country x Is Competitive in All Periods" for the Case of Argentina

\begin{tabular}{|c|c|c|c|c|c|c|c|c|c|}
\hline Greece & 0.03 & Malta & 0.50 & Bulgaria & 0.59 & Venezuela & 0.70 & Nigeria & 0.83 \\
\hline Germany & 0.07 & Panama & 0.51 & Chile & 0.60 & Malaysia & 0.71 & Peru & 0.84 \\
\hline Jordan & 0.14 & Thailand & 0.52 & Estonia & 0.60 & Canada & 0.71 & Italy & 0.88 \\
\hline Bolivia & 0.23 & Portugal & 0.53 & Belgium & 0.61 & T. Franc. (Am) & 0.72 & Singapore & 0.88 \\
\hline Republican Korea & 0.24 & T. Holan. (Am) & 0.53 & Denmark & 0.61 & Australia & 0.74 & Croatia & 0.88 \\
\hline Israel & 0.25 & Turkey & 0.54 & Sudan & 0.62 & Lebanon & 0.74 & Libya & 0.90 \\
\hline Paraguay & 0.33 & Indonesia & 0.54 & Switzerland & 0.63 & Romania & 0.78 & Cuba & 0.90 \\
\hline Cyprus & 0.36 & United Kingdom & 0.55 & Spain & 0.63 & Netherlands & 0.78 & United States & 0.93 \\
\hline New Zealand & 0.38 & Costa Rica & 0.55 & Mexico & 0.64 & Russia & 0.79 & Japan & 0.95 \\
\hline Taiwan & 0.39 & Finland & 0.56 & Gabon & 0.67 & Norway & 0.81 & & \\
\hline Brazil & 0.45 & Tunisia & 0.57 & Colombia & 0.68 & Ukraine & 0.81 & & \\
\hline South Africa & 0.45 & Serbia and Mont. & 0.57 & Hungary & 0.68 & Algeria & 0.82 & & \\
\hline Sweden & 0.45 & Zaire & 0.57 & Uruguay & 0.68 & Lithuania & 0.82 & & \\
\hline France & 0.47 & Philippines & 0.58 & Dominican Republic & 0.69 & China & 0.83 & & \\
\hline Slovenia & 0.48 & India & 0.59 & Poland & 0.70 & Morocco & 0.83 & & \\
\hline
\end{tabular}

\section{Conclusions}

Values close to 0 in Table 1 report the markets in which the Argentine fishery products are not competitive. By contrast, values close to 1 represent markets where the export sector, that is being study, is competitive. Because the competitiveness of Argentina fishery products is closely related to natural resource endowments (comparative advantages offered by the Argentine Sea), the risk associated with fluctuations in the availability of these is undoubtedly the greatest challenge facing the fishing industry in Argentina. That is the reason why the results observed in a number of countries in which the value obtained is or is close to 0.5. These markets represented permanent customers are stocked out by Argentina when the catch decreases for reasons related to the scarcity of resources and/or measures of government established for the purpose of conservation or recovery of fish biomass.

In order to supply large buyers in times of crisis, Argentina's fishing industry chooses to neglect the potential markets, though they are abandoned by their provider over the study period which demonstrate the intention to remain as importers of fishery products Argentines.

The results derived through the use of computer tools developed are consistent with the assumptions made by experts using other methods of work. The tool is an innovative approach, not only when applied to the Argentine fishing sector, but also for other industrial sectors that make up the country's productive system. 


\section{References}

Bonissone, P., Chen, Y. T., Goebel, K., \& Pratap, S. K. (1999). Hybrid soft computing systems: Industrial and commercial applications. Proceedings of The IEEE, 87(9), 1641-1667.

Contreras Castillo, J. M. (1999). La competitividad de las exportaciones mexicanas de aguacate: un análisis cuantitativo. Revista Chapingo Serie Horticultura, 5, 393-400.

D’Onofrio, M. V. (2008). Dinámica de la industria pesquera argentina en la década de los noventa. Contribuciones al desarrollo o deterioro del sector. Facultad de Ciencias Humanas, UNCPBA, Tandil.

D’Onofrio, M. V., Parín, M. A., \& Zugarramurdi, A. (2009). Performance exportadora de los productos pesqueros argentinos en el mercado de la unión europea. La Industria Cárnica Latinoamericana, 162, 50-55.

Espin Andrade, R. A., Suarez, A. R., \& Gomez, J. M. (2000). A general approach for knowledge discovery based on compensatory fuzzy logic and metaheuristic search.

IICA. (1992). Transformaciones productivas y competitividad. Instituto Interamericano de cooperación para la agricultura. IICA, San José de Costa Rica.

Meschino, G. J., Espin Andrade, R. A., \& Ballarin, V. L. (2008). A framework for tissue discrimination in magnetic resonance brain images based on predicates analysis and compensatory fuzzy logic. International Journal of Intelligent Computing in Medical Sciences and Image Processing, 2(X), 1-16.

Zadeh, L. A. (1994a). Fuzzy logic and soft computing: Issues, contentions and perspectives. Proc. of IIZUKA'94: Third Int.Conf. On Fuzzy Logic, Neural Nets and Soft Computing, pp. 1-2. Iizuka, Japan.

Zadeh, L. A. (1994b). Fuzzy logic, neural networks and Soft Computing. Commun ACM, 37(3), 77-84.

Zugarramurdi, A., Parín, M. A., Online, A. E., \& D’Onofrio, M. V. (2007). Comercio Internacional e Indicadores de Competitividad: El caso de la industria pesquera argentina. XI Congreso Argentino de Ciencia y Tecnología de Alimentos, Buenos Aires. 